\title{
The role of surgical procedures on discriminative performance of the updated euroSCORE II
}

\author{
Fabio Barili, MD, PhD, ${ }^{a}$ Davide Pacini, MD, ${ }^{b}$ Francesco Rosato, MD, ${ }^{a}$ and Alessandro Parolari, MD, PhD, \\ Cuneo, Bologna, and Milan, Italy
}

\begin{abstract}
The euroSCORE II has recently been developed to increase the performance of the older versions that have been demonstrated to be miscalibrated. ${ }^{1}$ Although the core of the algorithm is similar, some new pieces have been added, among them a different classification of operations and a novel categorization of number of procedures. Nonetheless, no data are available regarding the potential relationship between euroSCORE II performance and surgical procedures. The purpose of this study was to evaluate the impact of surgical procedures on euroSCORE II calibration by modeling the receiver operating characteristic (ROC) curve with a generalized linear model.
\end{abstract}

\section{MATERIALS AND METHODS}

Data on 13,871 consecutive patients who underwent cardiac surgery in a 6-year period were retrieved from the institutional databases that are prospectively collected within the departments of cardiac surgery of two university hospitals and one regional hospital in Italy. The relevant institutional review boards approved the data set's use for research. The Institutional Ethical Committees approved the study, and the requirement for informed written consent was waived on the condition that subjects' identities remain masked. Data from the three centers were matched and stored in a dedicated data set. The euroSCORE II was tested on the prediction of in-hospital mortality. Discriminative power was assessed with the c-index (area under the ROC curve [AUC]). To analyze the effect of type of surgery on discriminative power, we modeled the ROC curve with a parametric generalized linear model, with a binormal mode. ${ }^{2}$ Two-sided statistics were performed. For all analyses, the R 2.15.1 software was used. ${ }^{3}$

\section{RESULTS}

The mean value of euroSCORE II was $3.0 \pm 4.1$, and the observed mortality was $2.5 \%$ (335 patients). The mean age of the study group was $67.4 \pm 11.7$ years, and $31.4 \%$ (4359 patients) were female. A majority of the group underwent isolated or associated coronary artery bypass grafting (CABG; 7449 patients, 53.7\%).

\footnotetext{
From the Department of Cardiac Surgery, ${ }^{\text {a }}$ Santa Croce Hospital, Cuneo, Italy; the Department of Cardiac Surgery, ${ }^{\mathrm{b}}$ University of Bologna, Policlinico Sant'OrsolaMalpighi, Bologna, Italy; and the Department of Cardiovascular Surgery, ${ }^{c}$ University of Milan, Centro Cardiologico Monzino I.R.C.C.S., Milan, Italy. Disclosures: Authors have nothing to disclose with regard to commercial support.

Received for publication Feb 18, 2013; revisions received May 26, 2013; accepted for publication June 5, 2013; available ahead of print July 22, 2013

Address for reprints: Fabio Barili, MD, PhD, Department of Cardiac Surgery, Santa Croce Hospital, Via Coppino 26, 12100, Cuneo, Italy (E-mail: fabarili@ libero.it or barili.f@ospedale.cuneo.it).

J Thorac Cardiovasc Surg 2013;146:986-7

0022-5223/ $\$ 36.00$

Copyright (c) 2013 by The American Association for Thoracic Surgery

http://dx.doi.org/10.1016/j.jtcvs.2013.06.006
}

A preliminary nonparametric analysis of discrimination showed a worse performance of the euroSCORE II in the surgical subgroups not included in the algorithm, such as aortic valve surgery, mitral valve surgery, tricuspid valve surgery (AUC $0.80,95 \%$ confidence interval [CI] $0.77-0.83$ vs AUC $0.87,95 \%$ CI $0.83-0.91$ for procedures included in the algorithm; Figure 1)

The multivariable direct parametric modeling of ROC curves with generalized linear model methodology demonstrated that surgery of the mitral valve significantly lowers the discriminative performance of the euroSCORE II by affecting both parameters that define the ROC curve (intercept $-0.38 \pm 0.16 ; 95 \% \mathrm{CI}-0.68$ to -0.05 ; slope $-0.36 \pm 0.10,95 \% \mathrm{CI}-0.57$ to -0.15 ; Table 1$)$, leading to a curve that is closer to the diagonal line. The effect of other procedures is not significant, and the performances for these subgroups of patients are comparable to that for patients undergoing CABG.

\section{DISCUSSION}

Perioperative outcomes are known to be influenced by several parameters, including the type of surgical

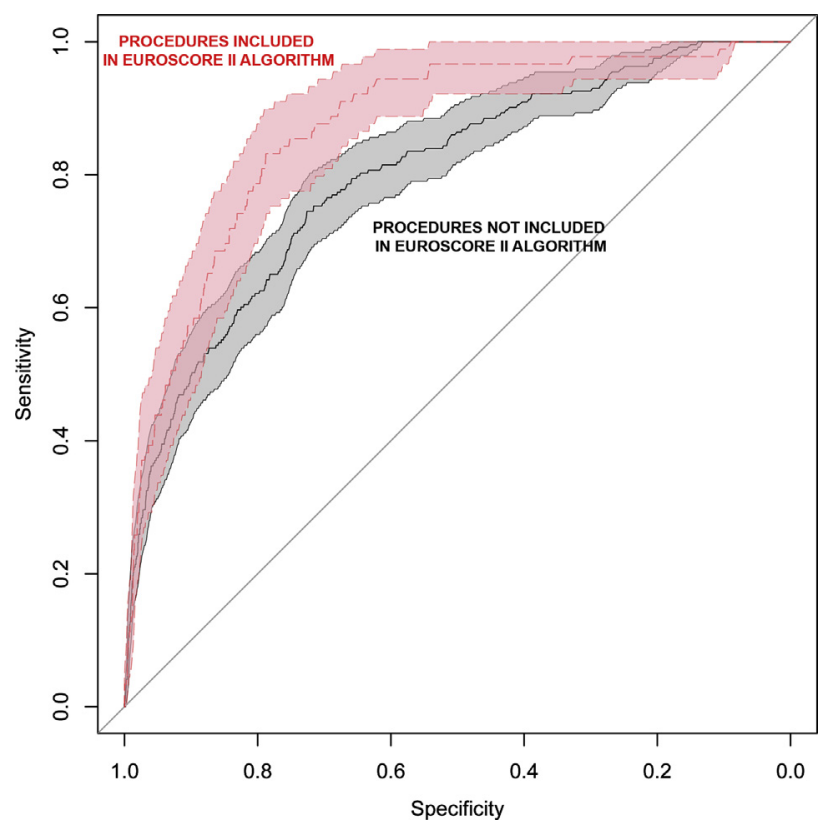

FIGURE 1. Receiver operating characteristic (ROC) curves for the EuroSCORE II in procedures included (CABG, surgery for aortic disease) and not included (such as aortic valve surgery, mitral valve surgery, tricuspid surgery) in the algorithm. The diagonal line represents no discriminatory power (area under the receiver operating characteristic curve of 0.50 ). 
TABLE 1. Parameters of the receiver operating characteristic curve after generalized linear modeling

\begin{tabular}{lccc}
\hline \multicolumn{1}{c}{ Surgical procedure } & Value & $\mathbf{9 5 \%}$ Confidence interval & $\boldsymbol{P}$ value \\
\hline Intercept & $1.22 \pm 0.10$ & $1.04-1.45$ & $<.05$ \\
Slope & $0.91 \pm 0.08$ & $0.78-1.1$ & $<.05$ \\
Effect of mitral surgery on intercept & $-0.38 \pm 0.16$ & -0.68 to -0.06 & $<.05$ \\
Effect of mitral surgery on slope & $-0.36 \pm 0.10$ & -0.57 to -0.15 & $<.05$ \\
\hline
\end{tabular}

Receiver operating characteristic curve is defined by 2 parameters, intercept and slope. The only covariate significantly affecting the receiver operating characteristic curve parameters was mitral valve surgery, which negatively affected discriminative performance.

intervention, and different surgical procedures are therefore expected to exert different effects on the prediction of in-hospital mortality. The Society of Thoracic Surgeons score was developed from data from distinct surgical populations, and the weight of procedures in risk prediction was underscored and included in the model. ${ }^{4}$ In contrast, the recently released euroSCORE II categorizes surgeries in general classes, privileging the role of the number of procedures without differentiating among non-CABG procedures. ${ }^{1}$ In this analysis, we have demonstrated that the discriminative performance of euroSCORE II is higher for surgical categories included in the algorithm, such as CABG or surgery for aortic disease, whereas it decreases in other classes. Nonetheless, the only covariate that significantly affects the ROC curve is surgery for mitral disease, which decreases the performance of the score. The discriminative power of euroSCORE II significantly worsens when applied to mitral surgery, although it still remains satisfactory (AUC 0.79 , 95\% CI 0.74-0.84). Previous validation studies have demonstrated good discrimination in the case of both isolated CABG and aortic valve replacement, although no composite evaluation of all surgical subgroups has been performed. ${ }^{5,6}$

The identification of independent predictors of discriminatory accuracy should lead to covariate adjustment or to the incorporation of such factors in the score algorithm. Nonetheless, further studies from larger data sets are needed to focus in addition on the roles of diverse surgical techniques for the same disease, because the classification of surgeries that we tested is generic. The general category "surgery for mitral disease," and also other surgical categories, includes different treatment options that can have an effect on outcomes.

The more complex categorization introduced in the updated euroSCORE II to update the older versions still seems inadequate. Further testing and refinement of the algorithm should include further surgical categories, and even subcategories.

\section{References}

1. Nashef SA, Roques F, Sharples LD, Nilsson J, Smith C, Goldstone AR, et al EuroSCORE II. Eur J Cardiothorac Surg. 2012;41:734-44; discussion 744-5.

2. Janes H, Longton G, Pepe M. Accommodating covariates in ROC analysis. Stata J. 2009;9:17-39.

3. R Development Core Team [Internet]. Vienna: R Foundation for Statistical Computing; c2011 [updated 2013 May 16]. The R Project for Statistical Computing. Available from: http://www.R-project.org/.

4. Shahian DM, O'Brien SM, Filardo G, Ferraris VA, Haan CK, Rich JB, et al. The Society of Thoracic Surgeons 2008 cardiac surgery risk models: part 3-valve plus coronary artery bypass grafting surgery. Ann Thorac Surg. 2009;88(1 Suppl): S43-62.

5. Biancari F, Vasques F, Mikkola R, Martin M, Lahtinen J, Heikkinen J. Validation of EuroSCORE II in patients undergoing coronary artery bypass surgery. Ann Thorac Surg. 2012;93:1930-5.

6. Grant SW, Hickey GL, Dimarakis I, Trivedi U, Bryan A, Treasure G, et al. How does EuroSCORE II perform in UK cardiac surgery; an analysis of 23740 patients from the Society for Cardiothoracic Surgery in Great Britain and Ireland National Database. Heart. 2012;98:1568-72.

\title{
Single-lung transplants: The fate of the second donor lung
}

\author{
Anne Olland, MSc, MD, Pierre-Emmanuel Falcoz, MD, PhD, FETS, Nicola Santelmo, MD, and \\ Gilbert Massard, MD, PhD, FETS, Strasbourg, France
}

\footnotetext{
From the Lung Transplant Program, Hôpitaux Universitaires de Strasbourg, Strasbourg, France.

Disclosures: Authors have nothing to disclose with regard to commercial support.

Received for publication Feb 26, 2013; revisions received May 16, 2013; accepted for publication May 31, 2013; available ahead of print July 15, 2013.

Address for reprints: Anne Olland, MSc, MD, Thoracic Surgery Department,

Hôpitaux Universitaires de Strasbourg, Nouvel Hôpital Civil, 67091 Strasbourg

Cedex, France (E-mail: anne.olland@chru-strasbourg.fr).

J Thorac Cardiovasc Surg 2013;146:987-9

0022-5223/\$36.00

Copyright (c) 2013 by The American Association for Thoracic Surgery

http://dx.doi.org/10.1016/j.jtcvs.2013.05.046
}

Patients listed for lung transplants still suffer from lack of available donor organs. In France between 2004 and 2009 , an average of 31 patients yearly died while on the waiting list. ${ }^{1}$ Single-lung transplants (SLTs) have the theoretic advantage of increasing access to transplantation by sharing a single donor between 2 recipients who become "twinned." Twinned SLTs (TSLTs) are feasible even in a single center, without impairment of outcome in the second recipient despite longer ischemia. ${ }^{2}$ The real benefit of TSLT 